\title{
Abaixo os miseráveis! Morram os assassinos! - os soldados avançam sempre: a heroicização do Coronel Genuíno Sampaio na batalha contra os Mucker
}

\author{
Down with these bastards! May all murderes perish!- soldiers march on: the making of Colonel \\ Genuino Sampaio as a hero in the battle against the Mucker
}

¡Bajo los miserables! jMueran los asesinos! - los soldados avanzan siempre:la construcción de la imagen heroica del Coronel Genuíno Sampaio en la Batalla contra los Mucker

\section{Resumo}

O artigo analisa a construção da imagem do Coronel Genuíno Sampaio, que morreu em combate na luta contra os Mucker, no final do século XIX. O grupo Mucker, liderado por Jacobina Mentz Maurer, organizou-se no morro Ferrabraz, localizado na Antiga Colônia Alemã de São Leopoldo - RS e foi derrotado pelas forças oficiais do exército brasileiro em 1874. Após o desfecho do conflito, procurou-se dar visibilidade à imagem heroicizada de Genuíno Sampaio, aspecto que se manifestou de forma evidente nas narrativas produzidas sobre o conflito. Neste estudo, discutimos a importância desempenhada pelos textos históricos, como elementos simbólicos de produção da memória, que foram responsáveis em grande parte, pela difusão de uma imagem de Genuíno Sampaio como herói da história.

Palavras-chave: Genuíno Sampaio. Herói. Memória.

* Doutor em História pela Universidade do Vale do Rio dos Sinos (Unisinos) e professor no Programa de Pós-Graduação em Desenvolvimento Regional das Faculdades Integradas de Taquara (Faccat) e no Instituto Superior de Educação Ivoti (ISEI).

Recebido em 10/07/2013 Aprovado em 30/07/2013 http://dx.doi.org/10.5335/hdtv.14n.1.4164 


\section{Considerações iniciais}

O movimento Mucker, ${ }^{1}$ no qual o Coronel Genuíno Sampaio - objeto de nossa análise - lutou como combatente, ocorreu no final do século XIX. Esse episódio se desenrolou entre 1868 e 1874, na antiga Colônia de São Leopoldo, atual município de Sapiranga - RS, envolvendo um grupo de colonos formado por imigrantes e descendentes de imigrantes alemães. Esse grupo, supostamente, estaria formando uma nova seita religiosa, de caráter messiânico, liderada por Jacobina Mentz Maurer e por seu marido João Jorge Maurer, conhecido como "o curandeiro". O conflito acaba com o extermínio desses colonos, pelas forças oficiais, lideradas pelo Coronel Genuíno Sampaio.

O casal Maurer liderava o grupo Mucker, constituído por cerca de 150 pessoas, ao qual Jacobina teria conferido um caráter de fanatismo, visto que, segundo relatos da época, as pessoas impressionavam-se e influenciavam-se diante dos acontecimentos aparentemente sobrenaturais por ela protagonizados. De acordo com a versão oficial, estes eram intencionais e teatralizados, com o objetivo de enganar os colonos que compareciam aos cultos.

Jacobina e Genuíno tiveram seu perfil e suas ações interpretadas a partir de diversos ângulos, que acabaram contribuindo, na maioria das vezes, para a construção de uma imagem detratora da primeira e heroica do segundo. ${ }^{2}$ Nesse caso, consideramos Jacobina e Genuíno como personagens antagônicos e que a narração das virtudes de um serviu de desqualificação para o outro, já que se encontravam em lados opostos. Assim, esses personagens tiveram uma memória ${ }^{3}$ produzida através dos antagonismos existentes e (re)produzidos por diferentes narrativas.

Para compreender o processo de construção dessas representações, consideramos que "as batalhas simbólicas para a construção de heróis envolvem tanto a memória histórica quanto o apelo a lendas e mitos" (OLIVEIRA, 2003, p. 68). De acordo com Oliveira, a origem das representações dos heróis da história nacional encontra-se precisamente na descrição "heroicizada" dos personagens, inscritas num campo de batalha simbólica. A autora afirma que, nesse campo de batalha, para se impor determinadas versões sobre os personagens, muitas vezes se recorre às narrativas de época e aos testemunhos orais, que, em alguns casos, confundem-se com versões lendárias e imaginárias em relação aos fatos e personagens do passado. A historiadora nos mostra, ainda, que as lendas e os mitos descrevem fatos ocorridos em uma temporalidade indefinida, naquilo que ela mesma define como "tempos imemoriais", que "falam de personagens sobre os quais não há dados históricos; mencionam viagens sem dados geográficos precisos" (OLIVEIRA, 2003, p. 68).

Assim, entendemos que houve um processo de construção de representações ${ }^{4}$ dos personagens emblemáticos do conflito $\mathrm{Mu}$ cker. Embora o conflito tenha envolvido uma grande quantidade de pessoas, tanto do lado dos Mucker quanto do lado de seus combatentes, priorizamos a análise das representações de Genuíno, pelo fato de esse personagem ter sua imagem glorificada por grande parte das fontes. Esse processo de enaltecimento de sua imagem é, aqui, objeto de nossa análise. 
Conforme veremos, parte das narrativas - entendidas, em nosso estudo, como representações perceptíveis nos textos historiográficos, portanto, portadoras de discursos - construídas sobre os Mucker procurou incutir no imaginário do leitor a noção de "verdade", levando a que o discurso do autor fosse legitimado pelos leitores, assumindo uma condição de portador de uma narrativa que descrevia de forma fiel os seus personagens e fatos.

Ressaltamos que, neste estudo, dedicamo-nos à análise das representações construídas sobre o Coronel Genuíno Sampaio, o que a distingue da maioria dos estudos sobre o tema Mucker atualmente, que tem privilegiado - de forma significativa - a atuação de Jacobina. Acreditamos que essa nova perspectiva justifica-se na medida em que nos preocupamos em entender como Genuíno passou de "herói", até o início do século XX, para a condição de personagem "esquecido" com as novas interpretações do conflito, que acabaram celebrando Jacobina como a nova "heroína". Buscamos, com isso, entender como se deu o processo de apagamento da imagem heroica do Coronel $\mathrm{e}$ como os novos estudos e o novo contexto de produção dessas narrativas acabaram contribuindo para a "fabricação" de uma nova imagem de Jacobina.

Iniciamos o estudo dos personagens centrais do conflito, apresentando, de forma abrangente, a biografia de Jacobina Mentz Maurer ${ }^{5}$. Pouco sabemos sobre suas características físicas, em razão de não haver qualquer retrato seu, o que a torna ainda mais enigmática, despertando o imaginário da população. A Jacobina criança teve sérias dificuldades na escola, não tendo conseguido aprender a ler e escrever quando criança. Segundo os diagnósticos do Dr. João Daniel Hillebrand, Jacobina apresentava, desde tenra idade, sinais de transtornos nervosos que haviam se agravado em sua fase adulta, quando iniciou a leitura e interpretação da Bíblia. De acordo com o médico, esses transtornos teriam provocado uma verdadeira mania religiosa e sonambulismo espontâneo.

Contrapondo-se às representações construídas e difundidas sobre Jacobina, encontramos aquelas que retratam o Coronel Genuíno Sampaio. Em nossa investigação, procuraremos analisar as diferentes representações construídas sobre o personagem Genuíno Sampaio e que foram veiculadas nos textos historiográficos mais conhecidos sobre o tema e que acabaram produzindo um impacto significativo na formação dos imaginários sociais.

Genuíno Olympio de Sampaio nasceu em 1822, na Bahia. Iniciou cedo sua carreira militar, tendo aos quinze anos de idade já participado, como cadete, no combate realizado contra os revoltosos no episódio da Sabinada, revolta que havia se iniciado em 1837, na Bahia. Pelos atos de bravura demonstrados naquela ação, Genuíno foi promovido a alferes de comissão. ${ }^{6}$

Com a eclosão do conflito na colônia alemã de São Leopoldo, o coronel foi chamado para apaziguar e acabar com o conflito entre os colonos do Ferrabraz. Foi durante essa ação que morreu, no dia 21 de julho de 1874. A causa de sua morte é bastante discutida, havendo diferentes versões. Alguns apontam a possibilidade de o Coronel ter sido atingido na perna por uma bala lançada 
por um Mucker, enquanto outros afirmam que a bala teria sido propositalmente lançada em sua direção por um soldado descontente. Já uma terceira versão aponta para a possibilidade de ter sido um de seus soldados o responsável pelo disparo, mas acidentalmente. Independentemente da origem do disparo, o fato foi que Genuíno veio a falecer em decorrência de uma forte hemorragia que não pôde ser controlada. A distância do Ferrabraz e os precários meios de transporte existentes na época impediram que o Coronel fosse levado em tempo até o centro de São Leopoldo.

O Coronel, que havia lutado em tantos outros combates, nos quais conquistara tantos títulos de bravura, tombou no Ferrabraz. Em razão de sua morte, entrou no cenário do conflito o major Dantas, que levaria o conflito até o final, com a derrota dos Mucker.

Diferentemente da personagem Jacobina, identificada como responsável pelo conflito, Genuíno Sampaio foi apontado pelas autoridades e consagrado à época dos acontecimentos - e nas décadas posteriores - como o herói do conflito. A representação construída sobre ele, e que se consagrou no imaginário da população de São Leopoldo, foi a do militar que tombou em nome da civilização contra a barbárie. Nesse caso, Genuíno representava a lança da civilização, enquanto os Mucker representavam o universo bárbaro, não civilizado.

Essas representações sofreram manipulações, especialmente a partir de 1889 , na medida em que o personagem é alvo de interpretação dos republicanos. ${ }^{7}$ A eleição desse personagem como figura heroica e de reputação inabalável foi indispensável para a condenação moral de Jacobina, que desempenhava a função de anti-heroína.

\section{A fabricação da memória do Coronel}

Na publicação do artigo "A fraude Mucker na Colônia Alemã. Uma contribuição para a história da cultura da germanidade daqui" (1875), encontramos a primeira imagem idealizada de Jacobina. Publicado por Carlos von Koseritz em seu Koseritz Kalender, o texto procura alertar as pessoas para os fatos que ocorriam, consistindo num "ato de denúncia" em relação ao grupo que se organizava no Ferrabraz. Para Koseritz, o movimento não se enquadraria na realidade da colônia alemã de São Leopoldo, o que justificaria a denúncia: "estes fatos lançam luz terrível sobre nosso progresso e que são motivo das mais sérias preocupações para o futuro" $(1875$, p. 1).

Apresentando os Mucker como fanáticos religiosos e avessos aos avanços da ciência, Koseritz tece críticas severas sobre eles, na medida em que não praticavam os valores da verdadeira germanidade ${ }^{8}$. Em sua exposição, o autor também aproveita para atacar de forma direta a ação da Companhia de Jesus, por ele denominada de agourenta Ordem de Jesus, o que expõe a rivalidade entre católicos e protestantes existente à época. $\mathrm{O}$ alvo preferido por Koseritz, no entanto, é Jacobina Mentz Maurer. Para ele, Jacobina era:

Uma mulherzinha doida, histérica como Jacobina Maurer teria sido simplesmente ridicularizada, sem jamais encontrar adeptos que se deixassem inflamar a tais atos macabros.

Sabemos de sobejo que com a publicação desta nossa opinião, baseada na mais intima convicção, haveremos de chocar nova- 
mente os mais amplos círculos. O agourento "S.v.K." será novamente o alvo da baba piedosa que espirra do alto dos púlpitos de ambas as confissões; hão de trovejar contra o almanaque popular e proibir a aquisição do mesmo - isso, contudo, pouco importa, pois cumprimos nosso dever, dizemos a verdade e esclarecemos os leitores a respeito das verdadeiras causas da fraude Mucker nas colônias (1875, p. 5).

A desqualificação de Jacobina no texto de Koseritz fica bem evidente no emprego do diminutivo mulherzinha. Jacobina é descrita como uma desajustada socialmente e responsável por atos macabros. Conforme o autor, se a população da colônia não tivesse vivido no desamparo religioso, Jacobina jamais teria alcançado o prestígio e a credibilidade que teve entre seus adeptos.

Na versão publicada sob o título Marpingen $^{9}$ und der Ferrabraz (1880), Jacobina é descrita como mensageira da palavra de Cristo. Para o autor, contudo, Jacobina não passava de uma enganadora. No texto, a atitude de Jacobina foi associada ao ambiente rude e hostil - de pouca formação intelectual -, bem como à ausência de amparo científico, que a privavam do conhecimento mínimo das leis que regem o universo (VON KOSERITZ, 1966, p. 172). Por sua vez, ainda que de forma indireta, Genuíno Sampaio é transformado em herói e responsável pela pacificação da Colônia, na medida em que foi quem enfrentou o grupo liderado por Jacobina no Ferrabraz. Assim, na perspectiva de Koseritz, Genuíno desempenhou um papel de pacificador, tendo grandes virtudes militares.

Em nosso estudo, consideramos necessária a análise do relatório escrito por Dantas em 1877, que liderou as tropas contra os $\mathrm{Mu}$ cker no Ferrabraz após a morte de Genuíno.
Isso se deve ao fato de sua versão ter influenciado de forma decisiva a produções de outros textos historiográficos sobre o tema. $\mathrm{Na}$ narrativa de Dantas (1877), prevalece o ponto de vista de um militar preocupado com a descrição do cenário e das ações militares que envolveram o combate dos Mucker. A ênfase dada a essas descrições fez que Dantas não se preocupasse em evidenciar o papel desempenhado por Jacobina. A ausência nominal da personagem, no entanto, não diminui a sua participação na organização do grupo, pois Dantas refere-se à casa como casa Maurer, numa referência ao casal. A casa Maurer, no entanto, é apresentada ao leitor como um símbolo da destruição dos Mucker, devido à ação militar bem-sucedida.

Comparada a uma pira gigante, a casa incendiada pelos soldados era motivo de comemoração de mais uma etapa na luta contra os Mucker. O cenário, mais uma vez, é enfatizado e associado ao terror, já que as vítimas teriam morrido queimadas, pondo fim à seita do Ferrabraz. Um aspecto, no entanto, chamou-nos a atenção: se os personagens envolvidos no conflito não mereceram um olhar especial por parte de Dantas, a atuação do Coronel foi enaltecida. Percebemos, ainda, sua preocupação em evidenciar a existência de dois grupos rivais. De um lado, os Mucker, identificados por ele como fanáticos que resistiram à determinação da lei, e, de outro, as forças oficiais que procuraram defender os interesses do governo e dos colonos que se viam atacados pelos Mucker.

Nesse contexto recriado por Dantas, Genuíno aparece como personagem de destaque, dada a sua atuação em combate, que acabou levando-o à morte. Ele é apresenta- 
do como "distinto coronel Genuíno" (DANTAS, 1877, p. 6), demonstrando a intenção de Dantas de enfatizar o caráter deste, que se perfilava entre os mais destacados militares brasileiros. As ações militares do Coronel foram ressaltadas na narrativa em análise, em que sobressaem sua bravura e seu perfil destemido e determinado ao combater os $\mathrm{Mu}-$ cker. Dantas compartilha com os leitores o momento em que Genuíno é atingido:

O coronel estava junto ao flanco direito e compreendendo o judicioso da minha observação, ordenou a esse flanco que avançasse. Pedi-lhe também que fizesse cessar as descargas inúteis que só serviam para com os clarões mostrar ao inimigo o lugar em que estamos. A voz do coronel a direita avançou (não tanto quanto convinha), mas fogo continuou ainda com a mesma intensidade. Dirigi-me para o centro e daí para a esquerda, onde estavam os artilheiros. [...]. Disseram-me daí a alguns minutos que o coronel fora ferido na perna levemente. Eram distintamente nessa ocasião só dois homens que atiravam da serra. Antes de clarear o dia já nem esses dois tiros se ouviam. Participaram-me haver morrido o coronel (DANTAS, 1877, p. 9).

Nesse trecho, tornam-se evidentes as recomendações de cautela dadas por Dantas a Genuíno. Este, segundo o autor, não teria se preocupado com os perigos, o que teria resultado no ferimento na perna, que o levou à morte ainda naquela madrugada do dia 20 de julho de 1874. Logo em seguida, Dantas refere a pouca importância estratégica daquele ataque noturno para o desfecho do conflito, não fosse a morte do Coronel. A morte de soldados e dos próprios Mucker foi entendida por Dantas como necessária, o que tornava a perda do Coronel ainda mais incompreensível e inaceitável:
À medicina compete explicar o fenômeno, só sei que perdeu grande quantidade de sangue e que não havia medico presente por haver na véspera se retirado com os nossos feridos o que acompanhara e expedição. $\mathrm{O}$ ataque da madrugada seria completamente sem importância se o destino não houvesse marcada com seu selo inexorável o termo dos dias do bravo coronel (DANTAS, 1877, p. 9).

A morte de Genuíno fora utilizada por Dantas para incentivar as ações dos soldados que, abalados com a morte do Coronel, viram-se numa situação difícil. Dantas afirmou que a morte de Genuíno deveria servir-lhes de exemplo de bravura e, estes não deveriam se deixar abalar. Ao contrário, deveriam tomar esse fato como lição e com isso "salvar a dignidade do uniforme nacional" (1877, p. 11).

Apesar de identificado pelo narrador como mal-aventurado, as incursões de Genuíno Sampaio deveriam servir de incentivo moral para todos prosseguirem no combate aos Mucker. Genuíno era, na interpretação de Dantas, exemplo de herói, que havia dado sua vida defendendo os interesses do Estado e da população da colônia alemã de São Leopoldo. Ao evidenciar o caráter cívico da atuação do Coronel, o autor ressalta a defesa dos interesses da pátria, contribuindo para a construção da imagem de um herói cujas características ímpares o tornaram vulto na história local, regional e nacional.

Concordando com a visão enaltecedora de Genuíno, o padre jesuíta Ambrósio Schupp ${ }^{10}$ desempenhou, segundo suas próprias convicções, o papel de verdadeira "testemunha ocular da história" (BURKE, 2004), afirmando que Jacobina e João Jor- 
ge Maurer eram os principais responsáveis pela formação do grupo, apresentando-os como o "casal misterioso do Ferrabrás [que] se deixou penetrar e possuir dessa convicção" (SCHUPP, s.d., p. 42).

Em sua descrição do movimento, o autor identifica a existência de dois grupos na área colonial: os Mucker e os Ímpios. Os Mucker eram os representantes das ideias fanatizadas de Jacobina e, os Ímpios, eram os representantes dos bons costumes e da sensatez. Além dessa referência à existência de dois grupos rivais, constata-se a plena identificação das ideias do autor com as das autoridades policiais. Isso fica evidenciado no uso da expressão "nosso delegado", revelando a posição favorável a um dos grupos envolvidos, o da repressão aos Mucker. Os esforços - narrativos - feitos por Schupp para identificar Jacobina como a líder espiritual do grupo e responsável pelos atos criminosos praticados pelos Mucker tornam-se perceptíveis no uso que faz de palavras e de frases de forte impacto, buscando sensibilizar o leitor e recriar o "ambiente de terror" no Ferrabraz.

Nessa mesma linha interpretativa, Schupp destaca a atuação de Genuíno Sampaio, afirmando que esta se deu a partir do momento em que as atividades do grupo liderado por Jacobina no Ferrabraz foram associadas a verdadeiros atos de barbárie. Como aponta em sua narrativa, o Ferrabraz havia se transformado num cenário de horror, no qual se realizava, por iniciativa de Jacobina, uma "festa de sangue" (SCHUPP, s.d., p. 217), disseminando um ambiente de "orgia de sangue nas picadas" (SCHUPP, s.d., p. 221). Nesse contexto, Genuíno re- presentou o grande salvador da população do Ferrabraz:

O comando da força foi confiado, pelo Presidente, ao Coronel Genuíno. De estatura meã, organização robusta, e, posto que não fosse moço, era Genuíno ainda vigoroso e cheio de energia militar. A sua fisionomia denunciava um ânimo corajoso e resoluto, e, com efeito, ambas as qualidades ele as possuía em grau elevado. As fadigas, durante a guerra do Paraguai, haviam-no curtido, e o concerto das balas inimigas o tornaram destemido, familiarizando-o com o perigo (SCHUPP, s.d., p. 246).

Como podemos perceber, Genuíno é representado com características que evidenciam suas qualidades físicas e morais. Schupp procura apresentá-lo como sendo dotado de virtudes que, nesse caso, serviram de contraponto à representação de Jacobina em sua obra. Termos como vigoroso, corajoso e resoluto tornam compreensíveis os objetivos de sua narrativa, que procurava construir a imagem do salvador, daquele que, mesmo podendo recusar tal empreendimento, agiu em nome de sua honra militar para livrar os colonos do domínio de Jacobina, como fica evidenciado na seguinte passagem: "Apressa-te, sê o nosso salvador, e, podes contar com as bênçãos de milhares de corações agradecidos" (SCHUPP, s.d., p. 246).

A ênfase dada à atuação de Genuíno favoreceu a construção de uma imagem de salvador reconhecida pela população, que lhe atribuiu a condição de verdadeiro herói. A identificação da população da colônia com as ações de Genuíno Sampaio foi tanta que muitos colonos ofereceram-se para ajudá-lo no combate aos Mucker. O ambiente de hostilidade ganha destaque na narrativa de 
Schupp, ao informar que "os fanáticos não vacilam, mas guardam o passo, amparando a investida. Aos brados de:- Abaixo os miseráveis! Morram os assassinos! - os soldados avançam sempre" (SCHUPP, s.d., p. 262).

$\mathrm{O}$ ataque que o acampamento das tropas imperiais sofreu teria sido provocado, segundo Schupp, pelo sentimento de vingança dos Mucker, despertado pelas ações realizadas por Genuíno Sampaio. Cabe lembrar que foi em conseqüência desse ataque dos $\mathrm{Mu}$ cker que Genuíno veio a falecer. Sua morte foi interpretada pelo autor como mais uma demonstração da violência e do fanatismo dos Mucker. A notícia da morte do Coronel é descrita a partir do profundo sentimento de consternação e de comoção que provocou:

A chegada do cadáver de Genuíno veio a confirmar a nova de sua morte.

No trem da tarde foram transportados para a capital o cadáver e os feridos. Se profundo tinha sido o abalo que produziu em S. Leopoldo a chegada do corpo de Genuíno, não menos aterradora foi a impressão que causou em Porto Alegre: aqui, nem sequer se suspeitava a triste ocorrência. Um frêmito de dor derivou pelas ruas, indo repercutir em todos os lares, quer ricos quer pobres. No dia imediato - 21 de julho - via-se desfilar um interminável préstito fúnebre, como talvez jamais se viu igual em Porto Alegre, e, à frente do cortejo, um caixão mortuário, ricamente coberto de crepe, era conduzido, à mão, por oficiais das mais altas patentes do exército. Era o ataúde do Coronel Genuíno (SCHUPP, s.d., p. 273).

O falecimento de Genuíno reforça a imagem heroica da personagem, já que esta se deu em combate. Sua atuação corajosa contra Jacobina e seus adeptos acabou sendo legitimada através do ritual que envolveu o sepultamen- to, realizado em Porto Alegre. Na passagem abaixo, Schupp procura enfatizar a simbologia presente no ritual de sepultamento:

Imediatamente após, acompanhado de todo o clero, vinha o bispo da diocese; seguindo-se a oficialidade, os corpos das diversas armas, e os altos funcionários públicos, e, fechando a procissão fúnebre, representantes das diversas corporações civis, negociantes, operários, e, por fim, uma multidão compacta de populares. Chegados ao cemitério, à beira da sepultura que devia guardar os despojos mortais do malogrado militar, entoou o Bispo o "De profundis". Um estremecimento de dor percorreu toda aquela multidão, e a muitos, sentindo o coração apertado pelos mais negros pressentimentos, marejaram as lágrimas (SCHUPP, s/d, p. 273).

Fica evidente a intenção do narrador ao descrever o ritual de sepultamento do Coronel: a de ressaltar a participação de diversas autoridades e da população da capital que, segundo ele, estavam comovidas e sensibilizadas com a morte de Genuíno. Na descrição que faz do sepultamento, Schupp enfatiza o sentimento de dor, a comoção e as lágrimas derramadas pelos presentes.

Diferentemente das versões apresentadas até aqui, Leopoldo Petry ${ }^{11}$ lança um novo olhar ao tentar compreender a personagem dentro de seu contexto. Para o autor, foram três os principais protagonistas do conflito, João Jorge Maurer, sua mulher Jacobina Mentz Maurer e seu concunhado João Jorge Klein. A partir dessa percepção, ele procura analisar as ações dos três personagens que, de acordo com seu entendimento, foram responsáveis pela organização dos Mucker.

O casal Maurer é descrito pelo autor como trabalhador, já que dentre os mora- 
dores do Ferrabraz, possuía as plantações e a moradia mais bem organizadas. Maurer é descrito como alguém de traquejo social e que teria agido de boa-fé no tratamento de doentes atendidos em sua própria residência no Ferrabraz, apontando as fofocas entre vizinhos como causadoras de boatos que procuravam difamar a reputação de Maurer. A Jacobina é apresentada como pertencente à classe das mulheres trabalhadoras, que ajudava o marido nas atividades agrícolas e também em sua nova profissão. Além dessas qualidades, o caráter religioso de Jacobina é evidenciado.

Para descrever o personagem Genuíno Sampaio, Petry recorre às memórias de seus familiares, pois crescera ouvindo seus pais falarem a respeito do conflito e dos personagens que se envolveram no episódio:

Conforme esclareci em outro capítulo deste trabalho, na casa de meus progenitores muitíssimas vezes se falou a respeito do episódio do Ferrabraz e mais duma vez ouvi dizer, nessas ocasiões, que o citado oficial fora morto por uma bala perdida de um tiro disparado pelos próprios soldados do Exército (PETRY, 1966, p. 90).

Constatamos que Petry apresenta Genuíno como um dos responsáveis pelo massacre ocorrido em 1874 no Ferrabraz. Apesar disso, não encontramos evidências que apontem para a condenação moral de Genuíno, na medida em que o autor o apresenta como alguém que desempenhou o papel de defender os interesses do Estado. Chamamos a atenção de que, na passagem acima, Petry traz-nos a versão de que Genuíno não teria morrido em decorrência de uma bala disparada pelos Mucker. Segundo ele, a morte de Genuíno foi provocada por um disparo da arma de um soldado comandado por ele próprio. Vale adiantar que, nessa descrição, o autor defende a inocência dos Mucker.

Para construir a narrativa, Petry valeu-se de testemunhos que, segundo ele, confirmam a versão ouvida desde os tempos de infância. Fundamental, nesse sentido, é o testemunho de Christiano Fischer, sobrevivente do campo de batalha, o qual lutou ao lado de Genuíno Sampaio, e confirma sua versão, assinando o depoimento:

Referindo-se à morte deste, declarou: que esteve no acampamento, na ocasião do tiroteio estabelecido na madrugada de 20 de julho, e que a bala que vitimou o Coronel, proveio de um tiro disparado por um dos soldados das fôrças legais nas imediações da casa onde se encontravam as prisioneiras, isto é, no flanco direito; que os disparos vindos do mato não podiam ter atingido o comandante das fôrças, devido à distância em que este se encontrava do ponto donde partiam; que naturalmente não foi possível distinguir a identidade dos atiradores, pois era noite escura e, portanto, impossível verificar quem atirava, ainda mais quando os autores dos tiros estavam no mato. Deixou ainda o senhor Fischer uma declaração assinada, confirmando suas afirmativas (PETRY, 1966, p. 91).

Cabe notar que a escuridão do ambiente é trazida como um elemento que pode indicar a imprecisão da autoria do disparo que vitimou Genuíno. Petry, através do testemunho de Fischer, questiona a versão oficial de que o Coronel Genuíno teria sido assassinado pelos Mucker, procurando desconstruir a sua imagem de assassinos. Ao mesmo tempo em que procurou inocentar os Mucker, o autor não deixou de empregar expressões que evidenciam o caráter de Genuíno, apre- 
sentado como "bravo militar e valoroso" (PETRY, 1966, p. 90). Essa opção leva-nos a acreditar na possibilidade de que Petry não quisesse difundir uma imagem negativa de Genuíno, mas sim situá-lo como um militar que desempenhou decisivo papel na defesa dos interesses do governo imperial ${ }^{13}$. Nesse sentido, a bravura e o caráter valoroso de Genuíno não poderiam ser desconsiderados em sua obra. Petry finaliza a narrativa sobre a morte do Coronel, posicionando-se da seguinte forma: "Pelo exposto não nos parece fundamentada a afirmação de ter sido obra dos 'mucker' a morte do bravo militar" (PETRY, 1966, p. 96).

Ao publicar sua obra em 1977, Domingues considera os estudos realizados até aquele momento, dedicando-se, sobretudo, a apresentar as diferentes interpretações construídas a respeito da personagem de Jacobina. $\mathrm{O}$ autor ressalta que, ao apresentar as diferentes interpretações sobre a personagem, tem a intenção de lançar-lhe um olhar desprovido de preconceitos, procurando avaliar o papel desempenhado por Jacobina em uma versão que não a apresentava como "anormal". O autor oferece-nos ainda a versão apresentada por Hillebrand, para quem Jacobina era uma paciente de difícil diagnóstico, embora afirmasse com convicção a sua boa fé. Domingues faz as suas considerações sobre a personagem. Para ele, Jacobina não podia ser caracterizada como paranormal, já que muitas de suas atitudes não passam defrutos de sua própria mente.

Bastante significativa para a análise que estamos fazendo é a publicação das memórias de Miguel Noé, anexas à obra de Domingues. Na versão apresentada por Noé, são apresentados novos elementos para sua condição de maior responsável pelo conflito. Para ele, a construção da imagem de Jacobina como fanática religiosa resultou da rede de intrigas existente na colônia naquele momento, solidificando a imagem do Coronel Genuíno como herói no imaginário social. Segundo seu depoimento, a rivalidade e o ódio instalados entre os moradores de São Leopoldo chegou a tal ponto que:

A campanha difamatória atingiu o ponto culminante. A agitação já havia atingido as crianças. Elas ouviam tudo de seus pais. Quando elas eram portadoras de uma faca, diziam orgulhosas: " - Com esta faca queremos fazer lingüiça de Jacobina!” (NOÉ, In: DOMINGUES, 1977, p. 391).

A posição assumida por Domingues quando se referiu à Jacobina deixa clara sua intenção de lançar um olhar mais crítico que aqueles lançados até então. Cabe ressaltar que sua obra insere-se no contexto da década de 1970, quando ocorre a publicação da Tese de Doutorado de Janaína Amado (1976) e do lançamento do primeiro filme sobre os Mucker (1978), que promoveram novas interpretações sobre o conflito. A obra de Domingues insere-se em um contexto - o da década de 1970 - no qual novas questões e abordagens eram lançadas sobre o tema Mucker. Assim, a versão apresentada por Domingues procura mostrar o uso de novas fontes, elucidando vários pontos obscuros sobre a história dos Mucker.

Domingues opta por evidenciar a atuação de Genuíno, apresentando-o a partir de sua capacidade de dirigir os soldados e colonos que compunham seu efetivo militar. Essa habilidade de organização é ressaltada por meio da composição do grupo que com- 
bateu os Mucker e que se encontrava sob o comando de Genuíno:

A força de Genuíno se compunha do $12^{\circ}$ Batalhão de Infantaria, uma ala do $3^{\circ}$ batalhão da mesma arma, uma bateria de artilharia, um Corpo de Cavalaria da Guarda Nacional e "um sem-número de paisanos armados, que se haviam oferecido para auxiliares, como conhecedores do terreno".

"Era considerável e mesmo excessiva a força para a quantidade de inimigos a combater" - pondera o capitão Dantas em sua parte oficial de $22 / 7$ - "não o era porém para aprender homens que tentassem fugir por cavernas e desfiladeiros só deles conhecidos" (DOMINGUES, 1977, p. 325).

O trecho torna evidente o fato de que o grupo combatente era numeroso e forte diante da pequena força representada pelos Mucker. A capacidade do Coronel é destacada no cerco feito ao Ferrabraz, para posterior ataque aos Mucker lá instalado. Domingues busca construir a representação de Genuíno como militar valente e digno da admiração de todos. Suas qualidades militares são enfatizadas pelo autor da seguinte maneira: “O coronel Genuíno, que era sem dúvida homem valente, digno de toda a nossa admiração, na linha de fogo dirigia o movimento debaixo de fogo incessante do inimigo, que disputava o terreno" (1977, p. 327). Valentia, coragem e honra eram qualidades que atestam a relevância do personagem no conflito.

\section{Consideracões finais}

A análise que realizamos sobre o Coronel Genuíno Sampaio permitiu que percebêssemos como, por meio das narrativas examinadas, a imagem do combatente dos Mucker foi construída e difundida em dife- rentes contextos e épocas. Notamos, ainda, que essas narrativas reafirmam o antagonismo existente entre os dois personagens principais do conflito, prevalecendo, até pouco tempo, a imagem heroica de Genuíno e a imagem anti-heroica de Jacobina.

A maioria das representações construídas a respeito dos dois personagens contribui para a construção da imagem de Jacobina como responsável pelas atrocidades cometidas pelos Mucker, ao mesmo tempo em que enalteceram as ações do Coronel nas operações militares no Ferrabraz. Embora Jacobina tenha sido, na maioria dos casos, o alvo das narrativas publicadas, é Genuíno quem ocupa o lugar de herói. A atuação de Jacobina é, na grande maioria dos relatos, utilizada para contrapor-se aos feitos "heroicos" de seu combatente. Sobre seu personagem recaíram os louros da vitória, e sua imagem é apresentada como a daquele que deu a própria vida em defesa dos interesses dos moradores de São Leopoldo e da pátria brasileira. O caráter cívico é amplamente enfatizado, destacando-se sua origem militar e seus feitos.

O olhar crítico que lançamos tem como objetivo avaliar as transformações ocorridas no processo de construção das representações sobre os dois personagens. Enfatizamos que nossa intenção não foi a de julgar, mas sim a de compreender como se deram as construções narrativas. Com isso, percebemos que, se num primeiro momento foi Genuíno quem se solidificou como herói no imaginário social, atualmente, esse lugar é ocupado por Jacobina, alvo de novos estudos e interpretações, resultandoem uma nova visão sobre a líder dos Mucker, não mais associada apenas ao papel de vilã na história. 


\section{Abstract}

The present article aims at analyzing the building of the image of Colonel Genuíno Sampaio, who died in the battle field against the Mucker, at the end of the XIX century. The Mucker, led by Jacobina Mentz Maurer, was organized in the Ferrabraz Mountain, which is located at the Old German Colony of São Leopoldo - RS and was defeated by the official military forces of the Brazilian Army in 1874. Upon the ending of the conflict, an effort has been made in trying to give notoriety to the heroic image of Genuíno Sampaio, an aspect that has become evident in the narratives produced about the conflict. In this study, we discuss the importance of historic texts as symbolic elements in the production of memory, which were responsible, to a great extent, for the spreading and the consolidation of the image of Genuíno Sampaio as a hero in history.

Keywords: Genuíno Sampaio. Hero. Memory.

\section{Resumen}

El artículo analiza la construcción de la imagen del Coronel Genuíno Sampaio, muerto en combate en la lucha contra los Mucker, en fines del siglo XIX. El grupo Mucker, liderado por Jacobina Mentz Maurer, se organizó en el monte Ferrabraz, ubicado en la Antigua Colonia Alemana de São Leopoldo - RS y fue derrotado por las fuerzas oficiales del ejército brasileño en el año 1874. Tras el desfecho del conflicto, se buscó darle visibilidad a la imagen heroica de Genuíno Sampaio, aspecto que se ha manifestado de forma evidente en las narrativas producidas sobre el conflicto. En este estudio, discutimos la importancia desempeñada por los textos históricos, como elementos simbólicos de la producción de la memoria, que fueron responsables en gran parte, por la difusión de una imagen de Genuíno Sampaio como héroe de la historia.

Palabras clave: Genuíno Sampaio. Héroe. Memoria.

\section{Notas}

1 O movimento Mucker ocorreu entre 1868 e 1874 na antiga Colônia Alemã de São Leopoldo - RS e envolveu imigrantes e descendentes de imigrantes alemães que, liderados por Jacobina Mentz Maurer, formaram um grupo religioso que se reunia em torno das leituras e interpretações da Bíblia realizadas por Jacobina. O conflito chegou ao fim em 1874 com a ação das tropas oficiais do Exército.

2 Consideramos significativas as contribuições trazidas por Candau, quando este afirma que as sociedades têm a necessidade de "refazer o passado", naquilo que ele traduz, sinteticamente, em três grandes operações simbólicas: "manipular, dominar e diferenciar" (2012, p. 164).

3 Le Goff nos ensina que a memória é um elemento essencial do que se costuma chamar "identida$\mathrm{de}^{\prime \prime}$, seja ela individual ou coletiva, cuja busca é uma das atividades fundamentais das pessoas e da própria sociedade. Nesse sentido, a memória não é apenas conquista, mas também um instrumento de poder. Existe uma luta pela dominação da recordação e da tradição, estabelecendo aquilo que deve ser lembrado e aquilo que deve ser esquecido (LE GOFF, 2003).

4 Não desconhecemos a diversidade de abordagens sobre as representações sociais; contudo, valemo-nos, especialmente, dos estudos realizados por Pierre Bourdieu, Roger Chartier e Bronislaw Baczko. Consideramos, também, extremamente válida a observação feita pela historiadora francesa Denise Jodelet de que "[as representações sociais] expressam aqueles (indivíduos ou grupos) que as 
forjam e dão uma definição específica ao objeto por elas representado. Estas definições partilhadas pelos membros de um grupo constroem uma visão consensual da realidade para esse grupo. Esta visão, que pode entrar em conflito com a de outros grupos, é um guia para as ações e trocas cotidianas - trata-se das funções e da dinâmica sociais das representações" (JODELET, 2001, p. 3).

5 Em relação a ela, sabe-se que nasceu em data desconhecida do mês de junho de 1842, na localidade de Hamburgo Velho, atual município de Novo Hamburgo - RS. Era filha do casal de imigrantes alemães André Mentz e Maria Elisabeth Muller, que, além de Jacobina, possuía mais sete filhos. Jacobina foi confirmada em 04 de abril de 1854 na Igreja Evangélica de Confissão Luterana do Brasil de Hamburgo Velho, onde viria a casar-se com João Jorge Maurer. Foi assassinada em 02 de agosto de 1874, quando foi descoberta, pelas forças oficiais, em seu esconderijo na mata fechada, ao pé do morro Ferrabraz.

6 Em 1838, Genuíno Sampaio chegou ao RS para lutar ao lado das forças imperiais na Revolução Farroupilha, que eclodiu na Província em 1835 e que se estendeu até 1845 . Terminada a revolução, foi elevado a tenente em 1847 e, em 1849, dirigiu-se à Província de Pernambuco para lutar na Revolução Praieira, que lá ocorria. Saindo do campo de batalha em Pernambuco, marchou até Montevidéu, no Uruguai, para lutar contra Rosas, ao lado do Conde de Porto Alegre. Em 1855, tornou-se capitão de $2^{\mathrm{a}}$ classe do Estado-Maior. Entre 1860 e 1863, trabalhou junto à Comissão Exploradora do Alto-Uruguai, e, no ano seguinte, foi nomeado ajudante do diretor da Escola Militar do RS. Participou da Guerra do Paraguai, o que lhe valeu a promoção a tenente-coronel efetivo devido aos seus atos de bravura. Mais tarde, já coronel, voltou ao RS, vindo a comandar a guarnição de uma parte da fronteira e, depois, fixando residência em Porto Alegre, onde comandava seu batalhão.

7 Em 1889, com a implantação da República no Brasil, o princípio que orientava as ações do novo governo era o lema positivista, de ordem e de progresso, corrente defendida por Augusto Comte. Sobre essa questão que envolve a implantação da República no Brasil e a manipulação dos imaginários sociais durante a consolidação do novo regime político, apontamos a obra $A$ formação das almas: o imaginário da República no Brasil, de José Murilo de Carvalho. Na obra, o autor discute a forma como os imaginários serviram de elemento fundamental para a consolidação da República e como a veiculação de representações sobre Tiradentes exerceu um papel indispensá- vel na construção de uma nova identidade para o novo regime político.

8 Lembramos que esta publicação ocorreu em meio às comemorações do $50^{\circ}$ Jubileu da Cidade de São Leopoldo, que, segundo Koseritz, eram alusivas à coragem alemã e pelo trabalho alemão. Ainda como exemplo da exaltação da germanidade, Koseritz refere-se aos imigrantes e seus descendentes como portadores do cerne operoso da natureza alemã e de natureza sadia da raça alemã.

9 Von Koseritz. In: PETRY, 1966. p.170-173. (Marpingen é traduzido por Petry como um lugarejo da Alemanha)

10 Schupp nasceu em Montabaur, Alemanha em 26 de maio de 1840. Cursou filosofia e teologia na Universidade de Würzburg. Chegou ao Brasil em 10 de outubro de 1874, após o término do conflito Mucker. Nos primeiros dezesseis anos no Brasil exerceu o cargo de Prefeito de Estudos no Colégio Nossa Senhora da Conceição, em São Leopoldo. Concomitante a essa função, exerceu o cargo de padre nas capelas de São Leopoldo, Hamburgerberg, Lomba Grande, Sapiranga e Mundo Novo. Em 1901, assumiu a direção do Seminário Episcopal e, em 1904, transferiu-se para Rio Grande, para dirigir o colégio da ordem jesuíta daquela cidade. Após essas atividades, finalmente atuou como professor no Ginásio São Luís, em Pelotas, vindo a falecer em 1914. Schupp consagrou-se no imaginário social da região do Vale dos Sinos como o portador da "verdadeira história dos Mucker", ideia compartilhada por muitos até poucas décadas.

11 Petry nasceu em 15 de julho de 1882, em Novo Hamburgo. Estudou no Colégio dos Jesuítas em São Sebastião do Caí, quando foi transferido para o Seminário Episcopal de Porto Alegre. Após os estudos, exerceu a função de professor em Novo Hamburgo. Foi secretário da Intendência Municipal de São Leopoldo e coletor estadual de Novo Hamburgo. Em 1927, com a emancipação política de Novo Hamburgo, passou a exercer a função de intendente daquele município até 1930 . Nesse ano Petry foi preso por não aderir à Frente Única, mas logo foi solto. Petry foi sócio do IHGRS - Instituto Histórico e Geográfico do Rio Grande do Sul e homenageado em 1955 com a medalha Imperatriz Leopoldina, concedida pelo IHGSP Instituto Histórico e Geográfico de São Paulo. Faleceu em 29 de novembro de 1966. A publicação da obra de Leopoldo Petry ocorreu pela primeira vez em 1957, a qual foi reeditada em 1966. e traduzida para o alemão por Theophilo Dietschi. Aobra sobre os Mucker foi alvo de inúmeras críticas, que a identificaram como uma tentativa de 
inocentá-los, recorrendo inclusive à omissão de informações que associavam os Mucker aos ataques praticados na época do conflito.

12

Em outro trecho da narrativa, Petry apresenta-nos outra possibilidade para explicar a morte de Genuíno Sampaio. Desta vez, ele recorre a um testemunho de um veterano da campanha dos "mucker" (PETRY, 1966, p. 94) que teria afirmado que os tiros disparados na ocasião da morte do Coronel teriam sido realizados pelos próprios soldados, que, pensando em se tratar de um ataque dos Mucker ao acampamento, confundiram os próprios colegas com os inimigos.

\section{Referências}

AHRS. Ligeira Notícia sobre as Operações Militares contra os Muckers na Província do Rio Grande do Sul. Francisco C. de Santiago Dantas. Rio de Janeiro, 1877, Maço 152.

CANDAU, J. Memória e identidade. São Paulo: Contexto, 2012.

CARVALHO, J. M. de. A formação das almas: o imaginário da República no Brasil. São Paulo: Companhia das Letras, 1990.

CATROGA, F. Os passos do homem como restolho do tempo: memória e fim do fim da história. 2. ed. Coimbra: Almedina, 2011.

DOMINGUES, M. A nova face dos Muckers. São Leopoldo: Rotermund, 1977. . A nova face dos Muckers. São Leopoldo: Rotermund, 1977.

JODELET, D. (Org.). As representações sociais. Rio de Janeiro: EDUERJ, 2001.

NOÉ, Miguel. Memórias. In: DOMINGUES, M. A nova face dos Muckers. São Leopoldo: Rotermund, 1977.

OLIVEIRA, L. L. A Construção do herói no imaginário brasileiro de ontem e hoje. In: PESAVENTO, S. J. (Org.). História cultural: experiências de pesquisas. Porto Alegre: UFRGS, 2003. p. 65-105.
PETRY, L. O episódio do Ferrabraz: os mucker. 2. ed. São Leopoldo: Rotermund, 1966.

SCHUPP, A. Os Muckers. 3. ed. Porto Alegre: Selbach \& Mayer, s.d..

VON KOSERITZ, C. A fraude Mucker na colônia alemã. uma contribuição para a história da cultura da germanidade daqui. Trad. de Martin N. Dreher. Koseritz Kalender, 1875.

. Marpingen und der Ferrabraz. In: PETRY, L. O episódio do Ferrabraz: os mucker. 2. ed. São Leopoldo: Rotermund, 1966, p. 170173. 